\title{
Cuidando ou tomando cuidado? Agressividade, mediação e constituição do sujeito - um estudo de caso sobre um bebê mordedor em creche
}

\author{
Rosaria Fernanda Magrin Saullo* , Maria Clotilde Rossetti-Ferreira** \\ Katia de Souza Amorim***
}

\section{Resumo}

O desenvolvimento do bebê é entendido, neste estudo, como biologicamente cultural e constituído por processos de mediação, inicialmente externa. Uma situação de crise foi investigada. 0 estudo de caso de um bebê mordedor (Vítor, 12 meses) foi oriundo de um projeto que acompanhou bebês em creche. A análise microgenética foi conduzida em material empírico formado pelo entrelaçamento de videogravações e entrevistas, tendo como base pressupostos histórico-culturais. Verificaram-se processos de mediação relacionados tanto a períodos particulares como ao drama das relações. A mediação foi dirigida não só à criança em estudo, como às educadoras e às demais crianças. Inicialmente, valorizou-se a aproximação entre estas, promovendo vínculos. Posteriormente, como Vítor revelasse comportamentos agressivos, passou-se a tomar cuidado com ele. Apesar da sua idade, as práticas pautavam-se em concepções ligadas a crianças maiores e adolescentes. 0 comportamento do bebê foi entendido como inato ou como problema de personalidade, o que levou ao seu relativo isolamento. No entanto, por meio de um referencial histórico-cultural, buscou-se novo olhar: a mediação representou um processo dialógico, com construção conjunta de significações/papéis e participação da criança. Sinaliza-se, aqui, a necessidade de novas investigações, essa discussão sendo particularmente útil à Educação Infantil.

\section{Palavras-chave}

Bebê; mediação; mordedor; significação; creche.

* Centro de Investigação sobre Desenvolvimento Humano e Educação Infantil (Cindedi), Faculdade de Filosofia, Ciências e Letras de Ribeirão Preto (FFCLRP), Universidade de São Paulo (USP), Ribeirão Preto, SP, Brasil. rosariasaullo@yahoo.com.br

** Departamento de Psicologia e Educação, FFCLRP - USP, Ribeirão Preto, SP, Brasil. mcrferre@usp.br

\section{*** Departamento de} Psicologia e Educação da FFCLRP - USP, Ribeirão Preto, SP, Brasil. katiamorim@ffclrp.usp.br 


\title{
Caring or being careful? Aggressiveness, mediation and constitution of the subject - $a$ case study of a biting baby in a daycare center
}

\begin{abstract}
Development is understood as occurring through mediation processes, which initially are external. To study that, a crisis situation was investigated. The case study of a biting baby was developed within a project which consisted in observing babies in a day care center. A microgenetic analysis was conducted through videorecordings and interviews. Mediation processes were identified, related not only to specific events, as well as to relational dramas. Mediation was not only directed to the boy, but also to caregivers and other children. Initially, the boy's movements of approach toward other children were appraised as promoting bonds. Later on, when behaviors became perceived as aggresive, adults began to be careful with him. Despite his age, adult attitudes towards him were based in conceptions about older children and adolescents behavior. His behavior was perceived as innate or as an indicator of a personality problem, leading the adults to isolate the child. However, based on cultural-historical perspective, mediation is considered a dialogical process, with meaning/role co-constructions, with children participation. The study highlights the need for further investigations, since such discussions are important for childhood education.
\end{abstract}

Keywords

Mediation; biting; signification; daycare center. 


\section{Introdução}

Tradicionalmente, na sociedade ocidental capitalista e, particularmente, na Psicologia do Desenvolvimento, quando se consideram cuidados dos filhos pequenos, a maior referência é a figura materna (Bowlby, 1990), considerada a cuidadora e a figura central no desenvolvimento da criança.

Contudo, devido a mudanças sócio-históricas e culturais, nas últimas décadas, a mulher tem cada vez mais participado do mercado de trabalho, e as mulheres-mães têm que reorganizar o cuidado dos filhos, para conciliar papéis de mãe, esposa e profissional (Rossetti-Ferreira et al., 2010). As instituições de educação coletiva aparecem, nesse contexto, como apoio, compartilhando com a família as tarefas de cuidar, socializar e educar, o que é dito como "triplo papel” dessas instituições (Zanella; Andrada, 2002). Com isso, a criança, que antes estava mais centralmente em casa com familiares, tem possibilidades de interação alteradas e ampliadas, com a participação, agora, de profissionais da educação, de pares de sua idade e de seus familiares (Amorim; Vitória; Rossetti-Ferreira, 2000; Rapoport Piccinini, 2001). Isso levou pesquisadores a investigarem processos de bebês nesses ambientes, a partir de novas abordagens.

Alguns desses estudos têm verificado que a participação do bebê passa por várias adaptações (Amorim et al., 2004; Amorim; Vitória; Rossetti-Ferreira, 2000; Rapoport; Piccinini, 2001). De acordo com esses autores, há a vivência de separações - diárias e temporárias - da criança de seus familiares, reorganizando suas relações (Salgado, 1999), estabelecendo relações entre educadora e familiares, algumas vezes, conflituosas (Amorim, 2002). 0 bebê passa a participar do ambiente com novas pessoas, com quem constrói novas relações (Eltink, 1999); e o parceiro mais frequente passa a ser o de sua idade, com quem interage (Amorim; Anjos; Rossetti-Ferreira, 2012; Costa, 2012). Gradualmente, ocorre a integração de um modo participativo da criança e de sua família ao grupo (Amorim et al., 2004).

Na convivência com os múltiplos outros, as atitudes do bebê são (re)significadas, conforme preceitos daquele grupo/instituição e dos familiares. São, então, atribuídos aos bebês certos papéis, que podem ser aceitos, recusados e/ou negociados, apesar de ele não possuir ainda linguagem verbal (Amorim; Anjos; Rossetti-Ferreira, 2012; Anjos et al., 2004).

Assim, já no primeiro ano de vida, a criança estabelece um repertório de comportamentos que permite que ela adquira novos estilos relacionais. Dá-se a (re)consti- 
tuição de sua subjetividade, a partir de contínuas negociações, no entrelaçamento do seu comportamento com a maneira como suas atitudes são interpretadas, em que todos têm papel ativo (Rossetti-Ferreira; Amorim; Silva, 2004).

O desenvolvimento se dá nas interações - reciprocamente constituintes - do bebê com vários outros e por meio delas. Nessas, os parceiros (particularmente os adultos) são vistos como mediadores, significando o mundo ao bebê e o bebê ao mundo, inserindo a criança em diferentes contextos e posições sociais (Rossetti-Ferreira; Amorim; Silva, 2004). Um dos teóricos a elaborar o papel e os processos de mediação no desenvolvimento do ser humano foi Vygostky (1991).

\section{A mediação e o desenvolvimento do bebê}

Em busca de compreender o desenvolvimento do pensamento e da linguagem, ao discutir mecanismos pelos quais a cultura se torna parte da pessoa, Vygotsky (1991) afirmou que, desde o nascimento, as atividades da criança adquirem significado dentro de um sistema de comportamento social. As ações do bebê são, dessa forma, entendidas segundo sistemas de representação do grupo em que está inserido, esse sendo o filtro por que a pessoa é capaz de ver e operar sobre o mundo. Por meio das relações, inicialmente, as ações da criança são mediadas pelo outro. Posteriormente, o processo interpessoal é transformado em intrapessoal (internalização), com a reconstrução da atividade psicológica com base em signos. Estes constituem novas formas de processos psicológicos, enraizados na cultura, mediando e controlando o próprio comportamento e tornando-se instrumentos para a compreensão do mundo e para a ação sobre ele.

Vale frisar que, apesar de entender que a estrutura da personalidade é social, para Vygotsky isso não significa que, no desenvolvimento, se é a reprodução do outro. A linguagem da criança não é a do adulto, pois a fala se vincula à atividade da própria criança, que produz algo novo, não necessariamente determinado pelos instrumentos usados para produzi-lo. Como afirma Oliveira (1993), a internalização da matéria-prima da cultura não é de absorção passiva, mas de transformação.

Quando se considera o bebê, portanto, destaca-se o papel da mediação externa sobre seu comportamento. Tomando isso por base, interroga-se como essas interações, mediações e (re)significações, com as inerentes negociações de papéis, ocorrem sem o uso da palavra, apesar de atravessadas por ela, uma vez que ainda não houve a internalização de signos verbais pelo bebê, tal como concebido por Vygostsky. 
Isso instigou a pergunta sobre como se dão processos de mediação, os quais contribuem para circunscrever a constituição da subjetividade da criança. Definiu-se, assim, por investigar tais processos por meio da análise da construção de papéis sociais no primeiro ano de vida, em interações que contribuem para (co)constituir o comportamento da criança. Dentre várias possibilidades, decidiu-se conduzir o estudo a partir de uma situação de crise, que dá maior visibilidade ao processo. Para isso, elegeu-se o caso de um bebê, em uma creche, que apresenta comportamento mordedor.

\section{Metodologia}

A coleta e a análise de dados foram orientadas pela "Rede de Significações" (Rossetti-Ferreira; Amorim; Silva, 2004; Rossetti-Ferreira et al., 2008). Ela considera que o desenvolvimento é biologicamente cultural, em que o bebê é inserido em diferentes ambientes e situações e perpassado por eles. A perspectiva traz, assim, a noção de construção conjunta pessoa-meio, mediada por situadas interações, e o desenvolvimento se dá nas interações com o outro e por meio delas. Essas interações são consideradas como campo interativo (Carvalho; Império-Hamburger; Pedrosa, 1997), como potencial de regulação recíproca entre componentes de um sistema, sendo implicitamente, e não necessariamente, intencional. A noção de interação engloba orientação da atenção, comportamentos socialmente dirigidos, regulação e corregulação.

Atenta-se, portanto, à complexa e constante dinâmica da relação pessoa-ambiente (Morin, 1990). Isso implica contextualizar desde o momento sócio-histórico e cultural, até as experiências e as interações situadas, conjunto esse que medeia o comportamento da criança, circunscrevendo - tanto possibilitando, como delimitando - a emergência de significações, interpretações e negociações nas relações.

Para atingir os objetivos - os processos de mediação do comportamento e desenvolvimento do bebê -, optou-se pela realização de estudo de caso. Este busca a análise de um sistema, do qual não é possível separar indivíduo-contexto, favorecendo a apreensão da sua complexidade. Segundo Yin (2005), o estudo de caso é usado quando questões da pesquisa se referem ao como se dão determinadas situações. Neste caso, como ocorrem a mediação, a atribuição/apropriação de significações e papéis, em situação em que estão presentes comportamentos agressivos em um bebê, em uma creche.

O estudo de caso permite também acompanhar o processo longitudinalmente, 
para verificar se/como certas condições mudam com o tempo. Finalmente, por ser estudo exploratório, já que se parte de hipótese controversa - bebês, antes da aquisição da linguagem verbal, já apreendem/expressam/negociam significações e papéis sociais.

Posto isso, será apresentado o caso, frisando que a pesquisa foi submetida e aprovada pelo Comitê de Ética em Pesquisa. Importante ressaltar que este estudo procurou tratar com cuidado e ética as questões e as discussões aqui levantadas, por considerar bastante delicado o estudo de tais crianças e situações.

\section{Projeto Integrado}

0 estudo foi realizado com o banco de dados do projeto "Processos de adaptação de bebês à creche", que acompanhou frequência de 21 bebês (4-14 meses), em uma creche de cidade do interior paulista. Os 21 bebês estavam organizados em turmas, de acordo com idade e habilidades, numa proporção aproximada de seis bebês para cada educadora.

Dentre os bebês, elegeu-se o sujeito pelo enfoque de crise. Especificamente, selecionou-se Vítor (nome fictício), que ingressou na creche aos 12 meses de idade, sendo filho único de casal em que o pai trabalhava na universidade e a mãe, não. 0 objetivo do casal, ao colocar o filho naquela instituição, era possibilitar à mãe a busca por emprego. Vítor se apresentava como uma criança grande, séria; praticamente não balbuciava e chorava pouco.

Para o projeto, foi feita uma série de registros, dentre eles entrevistas - realizadas semanalmente, por um semestre - com educadoras, técnicas e mães, e videogravações. Inicialmente, o objetivo foi obter informações relativas à adaptação de cada criança. Com o ingresso de todos os bebês, o foco voltou-se para seis crianças, consideradas "sujeitos focais".

As videogravações - um total de 75 horas - desenvolveram-se nos três primeiros meses e eram realizadas por uma hora seguida, registrando o conjunto dos eventos, guiadas por objetivos gerais, como reações e interações no momento de separação e reencontro da criança com familiares; apresentação do ambiente, de objetos e pessoas; interações da criança com educadoras e outras crianças. A importância das videogravações se deve ao fato de esse recurso possibilitar a preservação do fenômeno e propiciar a repetição da observação e mais tempo para reflexão, com enriquecimento da análise em foco (Carvalho et al., 1996). 
Das cenas, identificaram-se e editaram-se, cronologicamente, as 13 horas em que Vítor aparece. As cenas foram descritas, destacando local, pessoas presentes, atividades realizadas e interações estabelecidas, construindo-se um roteiro estruturado. Desse material, destacaram-se as interações amistosas ou agressivas, buscando compreender seu contexto. Pela análise preliminar das cenas, identificaram-se episódios que mostravam diferentes momentos do processo de significação e mediação da criança em seu papel de mordedor, esses sendo transcritos microgeneticamente (Amorim, 2002). Nessa análise, incluíram-se movimentos das pessoas e comunicações verbais e não verbais, caracterizadas por expressões faciais, gestos e posturas. 0 material foi articulado às falas das entrevistas referentes ao sujeito-focal (Vítor), a seu comportamento e a suas relações (e de seus familiares) no ambiente da creche.

Pela análise microgenética, os dados foram analisados no tempo em que o comportamento de mordedor foi sendo (des)(re)(co)construído. Essa análise, segundo Góes (2000), foca em relatos minuciosos dos acontecimentos, buscando configurar a gênese social, o caráter histórico e a relação do comportamento com planos da cultura.

\section{Resultados}

A creche em questão organiza o ingresso dos bebês no novo ambiente, para promover sua integração, de seus familiares e das educadoras no período de adaptação (usualmente uma semana). Assim, Vítor permaneceu acompanhado pela mãe. 0 fato que chamava a atenção na relação dos dois é que o bebê era reiteradamente interpelado pela mãe, quando ele se aproximava das demais crianças. A mãe chamava Vítor, em voz alta, pelo nome; e apontava-lhe negativamente os dedos. Apesar disso, nas cenas, não se evidencia comportamento de agressividade. Ao contrário, como mostra o episódio a seguir.

Este se deu no quarto dia de frequência, de que participam Juliana (10 meses) e Vitor (12 meses), além de Mirtes (educadora) e as mães de Vítor e Juliana. Na cena, Vítor e sua mãe estão sentados no colchão. Ele olha à volta. Em seguida, ele se afasta e engatinha em direção ao grupo em que Juliana se encontra. Quando esta o vê, ela também vai ao encontro de Vítor. Quando próximos, ambos na posição de engatinhar, as crianças tocam testa com testa, nariz com nariz. No movimento, Vítor cai pra trás, sentado, ao que sua mãe sorri. A seguir, ele vai novamente ao encontro de Juliana. Ambos 
alinham as cabeças, enquanto os adultos à volta sorriem. Na sequência, Juliana toma a iniciativa, a educadora dizendo: “Olha isso!". Quando sua mãe se aproxima, Juliana se vira. Com isso, ao fazer novo movimento de tocar a testa de Juliana, Vítor encosta a boca nos cabelos dela. Ela olha para ele e lhe estende a mão, ele dirigindo a boca às mãos dela. Rapidamente, a mãe de Vítor intervém e o afasta da outra criança.

Verificou-se aqui uma aproximação de Vítor, com comunicação não verbal aparentemente carinhosa das crianças, cujo encontro foi particularmente valorizado por estarem em adaptação. Mães e educadoras promoveram novos vínculos, e as ações dos adultos eram permeadas pelas suas expectativas relacionadas à fase do processo.

Essa expectativa de adaptação da criança deveria ser acompanhada por gradual maior afastamento da mãe do ambiente, ao final da primeira semana de frequência. Entretanto, o afastamento não ocorreu, tendo ela justificado sua permanência por diferentes questões.

Com sua permanência no ambiente, ela passou a ser vista como "mãe de primeira viagem", e suas posturas geraram, inclusive, certo incômodo. Repetidas são as cenas em que se observa a mãe interrompendo movimento de aproximação do filho de outro bebê. Também são recorrentes interpelações de “Não!” e “Vítor!”, que sinalizam a necessidade de estar atento a ele. Como diz a educadora Branca (08 abr.), “A mãe [...] ela fala pra mim 'Ai ele bate muito. Ele vai machucar alguma criança. Tem que olhar...' Ela já dá uma descrição da criança bem negativa...".

A dificuldade da mãe para deixar o ambiente da creche gerou ainda a crença de que o problema de adaptação de Vítor se relacionasse às dificuldades da mãe. Nesse sentido, a educadora Mirtes relata (24 mar.): “Ela é possessiva. Às vezes, sinto ela desconfiada, estranha...”. Ainda, como Branca diz (15 abr.), tinha temor de perda do amor do filho: "Ela falou assim: "Ele vai chorar, quer ver. Tchau, a mamãe vai embora!!!'. E ele ria e falava tchau pra ela. E ela voltava, 'Mas eu tô indo embora mesmo!”’.

Mais ainda, a educadora Branca (15 abr.) afirma:

Eu senti que... parece que ela não quer deixar ele ficar bem. Sabe aquele lance de que ele ficar bem não vai gostar de mim?... Ela pega todas as crianças e fica fazendo picuinha pra ele. Ela pega uma criança e fala "Olha nenê da mamãe, Vi. A mamãe tá com outro nenê!". 
O sofrimento da mãe tornou-se, gradualmente, pressão às educadoras, como Mirtes (29 abr.) explicita:

Eu aqui fazendo a maior festa com o menino e a mãe sofrendo... Eu me senti como se tivesse roubando aquele prazer que ela podia tá tendo. Eu me senti mal... Assim, fui me livrando. [...] "Tó! o filho é seu, o prazer é seu! Eu retiro de cena.".

Diante das dificuldades, as funcionárias se organizaram para lidar com a mãe e promover o afastamento. Simultaneamente, Vítor passou a mudar na relação com as outras crianças: intensificaram-se comportamentos bruscos (retirar a chupeta, puxar os cabelos), a ele, Vítor, sendo dados novos significados. A aproximação de Vítor passou a ser vista como ameaçadora às outras crianças. Cada aproximação e cada toque dele eram acompanhados por um olhar atento, por uma chamada de atenção e, até mesmo, por olhares assustados das demais crianças, que buscavam as educadoras, quando observavam maior proximidade de Vítor.

As aproximações se tornaram mais ávidas e bruscas, as mordidas passaram a ser mais frequentes, como a educadora Diva (29 abr.) relata:

Ele mordeu... é o tipo de criança que ele chega, ele morde onde der. E na Iraídes, além dele morder, ele enfiou a unha no olho e ele pegou o cabelinho dela e foi descendo até no chão. Ela gritou, ficou vermelha e ele mordeu na testa dela.... Se deixar, ele sai mordendo mesmo. Ele morde sério. Ele num se importa.

No contraponto à interpretação desse comportamento, outras explicações aparecem: "Não sei se é a maneira de ele chegar na outra criança. Ele não sabe a força que tem" (Viviane, educadora, 28 abr.).

Nas cenas, observa-se maior distanciamento em relação a ele. Diferentemente de outras crianças, Vítor era visto poucas vezes no colo. Há episódio, inclusive, em que a educadora se recusou a dar colo, mesmo quando solicitado, alegando que ele era grande. Apesar disso, imediatamente, ela pegou no colo outra criança de idade e tamanho semelhantes.

Essas ações de afastamento e evitação tornaram-se cada vez mais frequentes, 
como mostra o episódio a seguir (21 jun.), que ocorreu três meses após o anterior e do qual participaram Gilson (12 meses e 5 dias) e Vítor (12 meses), além de Milena (educadora). Na cena, as crianças e a educadora se encontram no solário. Vítor (camisa laranja) anda pelo espaço. Por fim, senta-se ao lado de Gilson (camisa listrada). Ao vê-lo, a educadora diz: “Viiiitor!”. Vítor se vira na direção da outra criança e aproxima sua mão dos braços dele. Rapidamente, a educadora se dirige aos dois e retira Gilson do chão, falando "Vamo sai do sol, vamo?". Apesar do "sol”, Vítor fica exatamente onde estava.

Essa cena aconteceu poucos dias depois de grave episódio de mordida (16 jun.), que acabou por desencadear uma série de reuniões dos pais com as educadoras. Como afirma Diva (22 jun.): “Essa mordida aí virou um episódio que... Os pais se dividiram entre prós e contra. Todo mundo acabou se envolvendo de alguma maneira". Houve pai, inclusive, que "falou assim: 'vocês deveriam bater... na criança que fez isso"”.

Entre as educadoras, continuou-se a buscar entender o comportamento da criança:

Ele não é daquela criança que chega e "nhac". Ele vai chegando de mansinho, dá aquele sorriso maroto, fica por ali, observa... Ele fica de marcação naquele amiguinho. Ele vai e volta; uma hora, ele vai lá, passa a mão; outra hora, ele vem e faz assim ó, gruda! Você tem que tá em cima, atenta aos movimentos (Mirtes, 16 jun.).

Branca (educadora) referiu que a mãe de Vítor se mostrava tensa com o episódio: "Ela falou: 'Esse menino é raça ruim, num sei o quê! Ele só faz essas coisas, fica judiando de todo mundo. Eu não posso ir em lugar nenhum, que ele só me faz passar vergonha...'. Tava, assim, muito brava. Falou que ele não ia voltar" (Branca, 17 jun.).

Em função de vários aspectos alegados pela família, um dos quais foi a mordida, dias depois, Vítor foi retirado da creche.

\section{Discussão}

Como explicitado, a meta do estudo foi investigar processos de mediação do comportamento de bebês, com atribuição/apropriação de significações e papéis, antes que aqueles tivessem adquirido linguagem verbal. $E$, de modo a ressaltar os processos, decidiu-se pelo acompanhamento de uma situação de crise - no caso, de um bebê mordedor, mais especificamente, Vítor, com 13 meses, ao início do estudo. 
O caso evidenciou transformação no comportamento da criança que, de mais recatada, quieta, protagonista de encontros amistosos (como com Juliana, na primeira cena descrita), passou a apresentar comportamentos mais agressivos. Inicialmente, esses se referiam a retirar objetos dos outros e a puxar os cabelos. Posteriormente, a mordida se tornou recurso privilegiado, crescendo em intensidade e frequência, chegando a atingir várias crianças em um mesmo episódio. Da fase de ingresso e adaptação ao final do semestre, as signific(ações) atribuídas foram até mesmo opostas.

Essa transformação foi se dando imersa em um contexto repleto de tensões: havia tensão pela preocupação da mãe com o filho (visto como agressivo); pelo temor de perda de amor do filho pela mãe (a mãe insistia na despedida ou, inversamente, provocava o filho, ao cuidar de outras crianças); pelo incômodo das educadoras com a presença da mãe; também, pelas dificuldades de manejo do comportamento de Vítor em relação às outras crianças e aos demais familiares. Esses comportamentos e as ações encontravam-se interligados na trama e no drama das relações (Vigotski, 1929), nos diferentes momentos em que as ações dos adultos se desdobravam de maneira diferente.

Destaca-se um dos elementos: o papel da mãe, que, reiteradamente, emitia preocupação com o "modo de ser” mais brusco do filho. Essa preocupação (e ações mediadoras) aparecia tanto dirigida ao próprio filho (recriminando, afastando), como às educadoras ("Ele bate muito, machuca, tem que olhar"). Ainda, as experiências vividas pelas demais crianças, entrelaçadas a essas mediações, resultavam em expressão de temor e busca de afastamento de Vítor. O comportamento gerou maior controle pelas educadoras e distanciamento de Vítor das crianças; parecia causar ainda incômodo na relação das educadoras com o próprio menino (não o pegando no colo, distanciando-se dele).

Assim, ao mesmo comportamento de aproximação e toque da criança foram atribuídas opostas signific(ações). Em contraponto aos sorrisos e ao estímulo à cena de delicadeza com Juliana, em meses posteriores verificaram-se concepções que aproximavam Vítor de um "sujeito perverso" ("ele não se importa", "raça ruim"), suas ações sendo vistas como carregadas de intencionalidade e planejamento estratégico ("chega de mansinho, com sorriso maroto"; "morde onde der; ele observa, fica de marcação e gruda!").

O problema era, ainda, tratado pelas bordas, realizando-se ações que desfocavam o comportamento de Vítor, atribuindo significações distintas e adotando práticas di- 
ferentes com as outras crianças, como na segunda cena em que, com a aproximação de Vítor, expressou-se preocupação com o sol. Porém esse cuidado foi dirigido apenas a Gilson, que foi afastado, tendo Vítor permanecido sozinho no local.

O que se observa é um padrão de ação diferenciado para Vítor: de cuidar passou a ser tomar cuidado com aquele bebê que mordia. Construía-se conjuntamente - e fazia-se sobressair - o papel da criança como o agressor, de quem se deveria manter distanciamento. Em busca de controle, Vítor passou a ser separado, afastado, evitado, chamado, interpelado, deixado em espaços com menor número de crianças. Os familiares das demais crianças passaram também a se manifestar, exigindo punição.

Essa questão (agressividade/mordida) e os modos de ação, no entanto, extrapolam o caso em estudo. Apesar das especificidades envolvidas, ele não é singular. A mordida representa evento comum e, às vezes, frequente na Educação Infantil, com desfechos até dramáticos (Ribeirão Preto on-line, 2010). Assim, embora o estudo de caso trabalhe com poucos sujeitos/condições particulares, sua análise permite o relacionamento entre singular e universal. Como Von Simson (2009) afirma, as vivências e as experiências pessoais revelam conteúdos do grupo social, elementos que circulam no imaginário social. Os casos não representam situações particulares somente, mas dialogam com - e neles estão imersos - elementos socioculturais, que contribuem para circunscrever os processos, permitindo que, com cuidado, se vá além do próprio caso.

Com isso, os discursos e as práticas dirigidas das educadoras (inclusive de silenciamento) encontram ecos e, simultaneamente, apropriam-se de discursos sociais sobre agressividade. Na literatura, a mordida é tema pouco evidenciado, havendo poucos artigos e relativo silenciamento. Quando esses aparecem, o assunto é usualmente abordado de maneira genérica, trazendo questões relativas à agressividade. Mais ainda, a maioria dos estudos não é feita com bebês, com algumas exceções. Greenman e Stonehouse (1994) afirmam que mordidas ocorrem normalmente em crianças de idade até 3 anos. Ao caracterizar as mordidas, alguns autores afirmam que elas são rápidas, efetivas e, geralmente, têm repercussões imediatas e dramáticas (Banks; Yi, 2007; Greenman; Stonehouse, 1994; Law, 2011; Legg, 1993; Stonehouse, 2010).

Essa caracterização, no entanto, contrapõe-se ao estudo de Costa (2012), que, ao estudar bebês em creche, verificou que as mordidas carregam sentidos diferentes, não têm todas o mesmo papel, apesar de o gesto ser o mesmo. Diferem também 
dessa caracterização alguns dos episódios apresentados por Vítor, que, segundo as descrições das educadoras, apresenta um comportamento de ir e vir, no entorno da criança, antes de mordê-la.

Essa particularidade chega a ser descrita pelas educadoras como um planejamento ("Olha, fica de marcação") e leva à compreensão de uma intencionalidade da criança, contrapondo-se à noção de Banks e Yi (2007), que afirmam que a mordida é raramente premeditada e ocorre no limite dos recursos disponíveis. Mas, se há o planejamento, como falar de intencionalidade de uso de força física ou ameaça que pode resultar em ferimento, nessa faixa etária? Como falar do bebê que "visa causar danos" e que, para isso, deveria ter noção de um outro que pensa e sente diferentemente dele; de uma meta de agressão, dentro de noções de temporalidade e consequência? A despeito da ainda não internalização de signos, estaria o bebê se apropriando de significações, papéis e noções de temporalidade por outros meios semióticos?

Outra questão é a forma como os adultos interpretam a mordida e a agressividade, interpretações essas que dialogam com o geral da literatura, em que se discute a questão em crianças usualmente mais velhas e até mesmo em adolescentes, falando de "desvio de conduta" (Scott, 1998), de problema de comportamento (Bolsoni-Silva; Paiva; Barbosa, 2009) ou de repertório comportamental negativo (Deynoot-Schaub; Riksen-Walraven, 2006). O que se verifica, nas falas da mãe e das educadoras, é a transposição e o uso de noções de agressividade atribuídas a outras faixas etárias, para o primeiro ano de vida, o que acaba por guiar as práticas de cuidados (ou de tomar cuidado).

Nessas interpretações, as falas transitam também no sentido de compreender a causa, e muitas atribuem o comportamento a algo inerente à personalidade, como particularidade do sujeito ("raça ruim"). Outras remetem à inadequação da mãe que, como Scott (1998), atribui a agressividade a problemas que derivam da interação dos pais. A ideia que permeia é de que problemas de agressividade estão relacionados ao repertório comportamental dos pais, os quais carecem de modelos desejáveis ao desenvolvimento das crianças (Bolsoni-Silva; Paiva; Barbosa, 2009). A agressividade é também vista como comportamento não adaptativo, em que a criança precisa de ferramentas de autorregulação para lidar de forma positiva/adaptativa (Mendes, 2009). Finalmente, outros a tratam como inata, como inerentemente humana e como parte do psiquismo (Andrade; Bezerra, 2009; Luz, 2008). 
Pelas falas das educadoras e da mãe, o que se verifica é a superposição de crenças de diferentes origens conceituais e a atribuição, à figura do bebê, de concepções sobre comportamento de sujeitos em outras fases de desenvolvimento. Com isso, a reflexão sobre as características dessa faixa etária e sobre a construção conjunta desses comportamentos (de que os adultos também participam) fica prejudicada, e o educador, os pais e as crianças ficam privados de outras possibilidades de percurso.

Para as educadoras, a situação é delicada. Como tratar a criança que morde, as repercussões dessa mordida e, ao mesmo tempo, atuar com a criança, com o parceiro machucado, com os pais bravos (outros familiares) e com os envergonhados (mãe do mordedor)? Como lidar com o cuidado de um bebê diferente, que desestabiliza a maneira tradicional (Otta; Bussab, 1998) e pede novos olhares? Como ver, então, "o que de bom tem o menino mau" (Maia et al., 2007, p. 341)? Como mediar o processo, se, de forma ambivalente, no momento em que se encontra uma explicação, retira-se do sujeito a culpa; ou, ao contrário, reforça-se a maldade que existe nele? Como mediar, para que o processo não resulte na cristalização de um rótulo (Greenman; Stonehouse, 1994), na constituição de estigma? Como embasar o cuidado e a educação, sem foco na contenção e na exclusão (que, no caso, levou à retirada da criança da creche)?

No caso de Vítor, que chegou a ser capaz de estabelecer bons contatos com outras crianças, não haveria outras possibilidades de mediação de suas potencialidades, de seu papel como ator do desenvolvimento, capaz de construir conjuntamente outras formas de comportamentos, numa diferente constituição subjetiva?

\section{Considerações finais}

O foco aqui lançado ao estudo de Vítor é destoante do geral da literatura, que não abarca a discussão da intencionalidade do mal. Na verdade, utiliza-se de noções vygostskyanas de mediação para apreender a constituição conjunta do comportamento, observando as diferentes significações construídas nas relações. Busca-se atentar para o processo de mediação e para o caráter dialógico e constitutivo das interações, visando lançar outro olhar à infância. Assim, outra postura poderia aflorar, não mais para conter e excluir, mas dispondo-se à compreensão do papel fundamental das interações na construção conjunta do processo de constituição do sujeito. No entanto, a construção desse saber - particularmente, do bebê como protagonista de seu desenvolvimento - é relativamente nova e ainda não abarca situações como a de comportamentos agressivos. 
As reflexões buscaram, assim, apreender um pouco do complexo e dinâmico processo de constituição conjunta do sujeito, propondo uma perspectiva interacional em que as concepções que transpassam o fazer da mãe e das educadoras circunscrevem as possibilidades de significação dos comportamentos apresentados pela criança.

Como observado, pode-se dizer que essa postura medeia e circunscreve, tanto abrindo como limitando possibilidades de transformação dessa situação, com repercussões na constituição da subjetividade da criança. Este estudo buscou ampliar esse olhar à criança, mas entende que o percurso foi apenas iniciado, havendo ainda um caminho a trilhar, de modo a não cair no mesmo viés de observar ao redor da criança mordedora, sem considerá-la como ativa no processo.

0 presente estudo ambiciona o diferencial, concebendo, sim, o ambiente e as relações como necessariamente constitutivos, porém não como determinantes; visa ainda colocar a criança como participativa no processo, na construção conjunta das significações e dos papéis em que está envolvida. Mas como apreender limites e possibilidades de atuação e construção de significações e papéis no seu próprio desenvolvimento, quando se fala do primeiro ano de vida?

0 processo é rico em discussões, reflexões e aprendizado, principalmente em relação a esta forma de estar no mundo: questionadora, visando sempre ao diálogo, em prol de construção de sentido. Uma fase se finda, mas um longo percurso se dispõe à frente. $E$, a cada passo, tornamo-nos mais intrigados para a caminhada. 


\section{Referências bibliográficas}

AMORIM, K. S. Concretizações de discursos e práticas histórico-sociais, em situações de freqüência de bebês a creche. 2002. Tese (Doutorado)-Universidade de São Paulo, Ribeirão Preto.

AMORIM, K. S.; ANJOS, A. M.; ROSSETTI-FERREIRA, M. C. Processos interativos de bebês em creche. Psicologia: Reflexão e Crítica, Porto Alegre, v. 25, n. 2, p. 378-389, 2012.

AMORIM, K. S. et al. Processos de adaptação de bebês à creche. In: ROSSETTIFERREIRA, M. C. et al. (Org.). Rede de significações e o estudo do desenvolvimento humano. Porto Alegre: Artmed, 2004. p.137-156.

AMORIM, K. S.; VITÓRIA, T.; ROSSETTI-FERREIRA, M. C. A rede de significações como perspectiva para a análise do processo de inserção de bebês na creche. Cadernos de Pesquisa, São Paulo, n. 109, p. 115-144, 2000.

ANDRADE, E. V.; BEZERRA JR., B. Uma reflexão acerca da prevenção da violência a partir de um estudo sobre a agressividade humana. Ciências da Saúde Coletiva, Rio de Janeiro, v. 14, n. 2, p. 445-453, 2009.

ANJOS, A. M. et al. Estudo de processos interativos de bebês. Estudos de Psicologia, Natal, v. 9, n. 3, p. 513-522, 2004.

BANKS, R.; YI, S. Dealing with biting behaviors in young children. 2007. Disponivel em: 〈http://ceep.crc.uiuc.edu/poptopics/biting.html〉 Acesso em: 10 jan. 2013.

BOLSONI-SILVA, A. T.; PAIVA, M. M.; BARBOSA, C. G. Problemas de comportamento de crianças/adolescentes e dificuldades de pais/cuidadores: um estudo de caracterização. Psicologia Clínica, Rio de Janeiro, v. 21, n. 1, p. 169-184, 2009.

BOWLBY, J. Apego. 2. ed. São Paulo: Martins Fontes, 1990.

CARVALHO, A. M. A. et al. Registro de vídeo na pesquisa em Psicologia: reflexões a partir de relatos de experiência. Psicologia: Teoria e Pesquisa, Brasília, v. 12, n. 3, p. 261-267, 1996.

CARVALHO, A. M. A.; IMPÉRIO-HAMBURGER, A.; PEDROSA, M. I. Interaction, regulation and correlation: a conceptual discussion and empirical examples in the context of human development. In: LYRA, M.; VALSINER, J. (Org.). The construction of psychological processes in the course of interpersonal communication. Norswod: Ablex, 1997. p. 135-151.

COSTA, C. A. Significações em relações de bebês com seus pares de idade. Dissertação (Mestrado em Psicologia)-Universidade de São Paulo, Ribeirão Preto, 2012. 
DEYNOOT-SCHAUB, M. G.; RIKSEN-WALRAVEN, J. M. Peer interaction in child care centres at 15 and 23 months: stability and links with children's socio-emotional adjustment. Infant Behavior Development, Amsterdan, Holanda, v. 29, n. 2, p. 276288, 2006.

ELTINK, C. F. Indícios utilizados para avaliar o processo de integração de bebês em uma creche. Dissertação (Mestrado)-Faculdade de Filosofia, Ciências e Letras de Ribeirão Preto, Universidade de São Paulo, Ribeirão Preto, 1999.

GÓES, M. C. R. A Abordagem microgenética na matriz histórico-cultural: uma perspectiva para o estudo da constituição da subjetividade. Cadernos CEDES, Campinas, v. 20, n. 50, p. 9-25, 2000.

GREENMAN, J.; STONEHOUSE, A. W. Reality bites: Biting at the center-Part 1. Child Care Information Exchange, Redmond, Estados Unidos da América, n. 9(94), p. 85-88, 1994 .

LAW, M. B. Biting questions. When a toddler bites, how do you handle the biter, the victim and both sets of parents? Monitor in Psychology, Washington, Estados Unidos da América, v. 42, n. 2, p. 50, 2011.

LEGG, J. What's a little bite among friends. Child Care Information Exchange, Redmond (Estados Unidos da América), n. 7(93), p. 41-42, 1993. Disponível em: 〈www.secure. ccie.com/catalog/search.php?search= biting〉. Acesso em: 15 de novembro de 2012

LUZ, I. R. Agressividade na primeira infância. Um estudo a partir das relações estabelecidas pelas crianças no ambiente familiar e na creche. São Paulo: Cortez, 2008.

MAIA, M. V. C. M. et al. Crianças "impossíveis": quem as quer, quem se importa com elas?. Psicologia em estudo, Maringá, v. 12, n. 2, p. 335-342, 2007.

MENDES, D. D. et al. Estudo de revisão dos fatores biológicos, sociais e ambientais associados com o comportamento agressivo. Revista Brasileira de Psiquiatria, Rio de Janeiro, n. 31, suplemento 2, S77-S85, 2009.

MORIN, E. Introdução ao pensamento complexo. Lisboa: Epistemologia e Sociedade, 1990.

OLIVEIRA, M. K. Vigotsky - aprendizado e desenvolvimento, um processo histórico. São Paulo: Scipione, 1993.

OTTA, E.; BUSSAB, V. S. R. Vai encarar? Lidando com a agressividade. São Paulo: Moderna, 1998.

RAPOPORT, A.; PICCININI, C. A. O ingresso e adaptação de bebês e crianças pequenas à creche: alguns aspectos críticos. Psicologia: Reflexão e Crítica, Porto Alegre, v. 14, n. 1, p. 81-95, 2001. 
RIBEIRÃO ON-LINE. Criança é agredida em creche do HC de Ribeirão Preto. 2010. Disponível em: 〈http://www.ribeiraopretoonline.com.br/noticias/crianca-e-agredidaem-creche-do-hc-de-ribeirao-preto/38076>. Acesso em: 20 abr. 2012.

ROSSETTI-FERREIRA, M. C.; AMORIM, K. S.; SILVA, A. P. S. Rede de significações: alguns conceitos básicos. In: ROSSETTI-FERREIRA, M. C. et al. (Org.). Rede de significações e o estudo do desenvolvimento humano. Porto Alegre: Artmed, 2004. p. 23-34.

ROSSETTI-FERREIRA, M. C. et al. Desafios metodológicos na perspectiva da rede de significações. Cadernos de Pesquisa, São Paulo, v. 38, n. 133, p. 147-170, 2008.

ROSSETTI-FERREIRA, M. C. et al. Peer relations in Brazilian daycare centers: a new focus for early childhood education. In: KERNAN, M.; SINGER, E. (Org.). Peer relationships in early childhood education and care. Abingdon: Routledge Education List, 2010, v. 1, p. 74-87.

SALGADO, H. O. (1999). Momentos no processo de adaptação de bebês à creche, com particular atenção à emergência de significações na coconstrução da relação mãebebê. Monografia (Bacharelado)-Universidade de São Paulo, Ribeirão Preto.

SCOTT, S. Aggressive behaviour in childhood. British Medical Journal, Londres, Inglaterra, v. 316, n. 7126, p. 202-206, 1998.

StOnehouse, A. A sensitive issue: Biting in child care. Putting Children First, Australia, n. 33, p. 14-16, 2010.

VIGOTSKI, L. S. Manuscrito de 1929. Disponível em: 〈F:Iscielo.php.htm〉Acesso em: 22 out. 2007.

VON SIMSON, O. R. M. Memória, cultura e sociedade do esquecimento. In: SEMANA DA PSICOLOGIA DA FACULDADE DE FILOSOFIA, CIÊNCIAS E LETRAS DE RIBEIRÃO PRETO, 2009, Universidade de São Paulo, Ribeirão Preto. Apresentação.

VYGOTSKY, L. S. A formação social da mente. São Paulo: Martins Fontes, 1991.

YIN, R. K. Estudo de caso - planejamento e métodos. Porto Alegre: Bookman, 2005.

ZANElLA, A. V.; ANDRADA, E. G. C. Processos de significação no brincar: problematizando a constituição do sujeito. Psicologia em Estudo, Maringá, v. 7, n. 2, p. 127-133, 2002.

Submetido à publicação em 11 de março de 2013.

Aprovado em 04 de junho de 2013. 